\title{
LAST PLANNER, EVERYDAY LEARNING, SHARED UNDERSTANDING \& REWORK
}

\author{
Alan Mossman ${ }^{1}$ and Shobha Ramalingam²
}

\begin{abstract}
Tasks most likely get done right when the performers' criteria match the criteria of those who receive the completed task (the customers). Knowledge in construction is mostly tacit. Making the tacit explicit is challenging and has to be conversational. Everyday learning and the structured planning conversations in the Last Planner ${ }^{\circledR}$ System (LPS) can help make tacit knowledge explicit. This conceptual paper explores the connections between learning, understandings of criteria and rework in project-based production to understand, how can we reduce rework on projects that arise from performers' misunderstanding of customer criteria for each task?

The preliminary findings are a) Less rework will be required when performers can develop a shared understanding of the criteria for each work task with their customers; $b$ ) Shared understanding is most likely when the criteria are explicit; c) Everyday learning will enable the process of making tacit information more explicit.

This paper has implications for practitioners as everyday learning and shared understanding will help workers at all levels to continuously share and learn while feeling psychologically safe enough to make mistakes and learn from them. It also suggests further multi-disciplinary research in the area of shared understanding and rework.
\end{abstract}

\section{KEYWORDS}

Reliable promising, Last Planner® System, flow, rework, everyday learning.

\section{INTRODUCTION}

Pasquire (2012) discusses common understanding and the consequences for production of 'not understanding' the 'what, how and why' to do something and that shared understanding can reduce snagging (punch) lists and the need to revisit work. Pasquire and Court (2013) showed how bringing together the knowledge distributed within a production team appeared to help the team get closer to a shared understanding of a project. Pasquire and Ebbs (2017) reiterate the value of shared understanding as an underpinning flow in lean construction. Using the metaphor of machine code, the code that controls the operation of machines, they suggest that, without good machine code, machine output is poor. In human systems, shared understanding is like good machine code. It needs to be supported by good leadership. To establish pre-conditions for communication and collaboration in construction projects, Koskela et al (2016) discuss the different meanings associated with the construct shared understanding. The article discusses six concepts that are potentially relevant to engaging in meaningful discussion.

\footnotetext{
The Change Business; +44 7968 485627, alanmossman@ mac.com, orcid.org/0000-0003-1769-9164

Associate Prof, National Institute of Construction Management and Research (NICMAR), Pune, India, sramalingam@nicmar.ac.in, orcid.org/0000-0003-4026-5866
} 
Ideas discussed in these papers are relevant to creating shared understanding at task level e.g. situational awareness, standard method, common ground, the importance of paying attention to tacit knowledge and making it more explicit.

In construction projects, rework is a significant source of time and cost escalation. Studies suggest $5-10 \%$ of project cost is generally spent on rework (i.e. more than the project margin claimed by many lead constructors). Some researchers claim it is over $20 \%$ and some rework events are hidden and unreported (Love 2020).

Learning is the basis for improvement. When a mistake is made and learned, people are far less likely to make the same or a similar mistake again (Ferrada et al. 2016). Although she makes reference to After Action Reviews and similar micro-learning processes, Carrillo (2005), like Ferrada et al, writes about macro-level stage-gate or endof-project lessons-learned systems. The lessons that participants will admit to learning are those that are not too embarrassing and will not trigger a claim from another party. Episodic learning like this contributes little to developing a learning culture.

Everyday learning is the basis for everyday improvement. It leads to small improvements made every day or every week that change the way things are done for the rest of the project. When a mistake is made and learnt from, the chances of making the same mistake again are reduced. This fosters a learning culture in projects and embeds improvements are more likely to be carried over to future projects as ingrained habits. This led us to want to understand what stops everyday learning in projects?

Our literature review throws light on several enablers of learning: leadership, motivation, face-to-face interactions, individual/team/organizational learning; and on disablers such as: time pressure, distance, virtual interactions, lack of management support, cultural differences (Gil and Mataveli 2017, Ferrada et al. 2016). Project mood can either support or obstruct learning (Flores 2016). Thus there are multiple constructs to explore. Taking a systems perspective and aligning with the core lean goal of delivering value, one significant input is reliable promising - using the promise cycle and success criteria or Conditions of Satisfaction (CoS) (Flores 2013). The process of conversation is nonetheless beset with challenges such as the psychological safety needs of team members (Edmondson 1999) or making tacit project knowledge explicit (Nonaka 1994). Failure to understand customers' CoS may lead to rework and delay in projects (Ballard 2000; Chiu et al 2016). Intuitively, it is therefore intriguing to understand the connection between learning, shared understanding, the $\mathrm{CoS}$ and rework in project-based production. This paper thus explores this research question: how can we reduce rework on projects that arise from misunderstanding the CoS? through literary evidence and experiential insights in the subsequent sections.

\section{METHOD}

This is a conceptual paper grounded in theory. Literary evidence is the basis for understanding real-life situations through inductive logic. The researchers' experiential knowledge and insights are an important part of the inquiry and critical to understanding the phenomenon (Sutton and Staw 1995). The focus is on complex interdependencies and system dynamics that cannot be reduced in any meaningful way to a few discrete variables or to linear, cause and effect relationships (Torraco 1997). Mindful of and attentive to system and situation dynamics, this study examines real-world situations as they naturally unfold with a focus on individuals, an organization, a community, or an entire culture. This method is the basis for understanding the connection between shared understanding, $\mathrm{CoS}$ and rework and also for future validation. To address the above research question, 
theoretical insights from literature and experiential evidence are discussed below in the context of the construct 'understanding':

\section{'UNDERSTANDING'}

Taking a systems perspective, 'understanding' is explored in the following sequence: $\mathbf{1}$. Focussing on the production, the promise cycle and the $\mathrm{CoS}$ as an input parameter for a shared understanding and learning in projects are investigated; 2. Focussing on the process, the challenges in learning with respect to transferability of tacit knowledge and embedded psychological safety issues in teams are explored; 3. Focussing on the output, the impact of poorly shared understanding that may lead to rework, added cost and delay in projects are highlighted and finally, 4. The insights on shared understanding and rework are integrated for a comprehensive and holistic understanding.

\section{1 'UNDERSTANDING' PRODUCTION AND THE CONDITIONS OF SATISFACTION}

Construction projects are a form of production. Production operations are broken down into discrete tasks. Tasks get done when they satisfy the requirements - the Conditions of Satisfaction $(\mathrm{CoS})$ - of the customers for that task. Subsequent trades, designers, the lead constructor, end-users, permitting authorities are all examples of customers for trade teams working on construction sites or in off-site fabrication shops. Customers provide critical inputs to the performers that increase the chances that the performers' outputs (decisions, designs, product) will be right-first-time and can be relied upon.

This means that there is a unique definition of value and unique $\mathrm{CoS}$ for every task within a project as well as for the project as a whole. Ideally each performer works with their unique $\mathrm{CoS}$ for each activity to:

- deliver the work safely and right-first-time meet the needs of the end-user or purchaser + authors of the directives and

- satisfy the next team(s) \&/or individual(s) that rely on the performer's output.

A successful handover requires the supplier to supply what the customer wants, when she wants it and how she wants it. In this context, effective project participants should understand their own needs and the needs of all their customers (for whom they provide inputs) and their suppliers, including designers (whose outputs they receive along with the CoS) (see Joseph Juran's triple role concept in Forbes and Ahmed 2010). Smooth handovers from one performer to another are critical to the success of a project, just as they are in a relay race. These handovers are often more than simple transmissions (or transitions). In athletics, those involved in a relay get to practice, review and improve over and over again. It is often the handover that makes, or breaks, a relay team. In projects, every handover is different and opportunities for rehearsal are limited.

On traditional projects, it is generally assumed that the instructions the workers are given are sufficient for them to understand what needs to be done. The problems of traditional construction project organisations have grown worse over the last 50 years as the construction sector has become ever more fragmented and worker employment more casualised (Green 2010). This has resulted (in UK, US, EU, India and elsewhere) in the use of workers who often don't share the language and culture of site and project managers. The results in linguistic, social, cultural and employment distance between crews and other project team members. This appears to reinforce site and project manager's tendency to tell workers what to do. 
On lean projects using the Last Planner System (LPS), work crew leaders decide for themselves what tasks they will do, when and how in ever increasing detail as the time to do a task gets closer. They use a series of structured planning conversations (Mossman 2020) with fellow crew leaders and site managers to do that. These conversations can help create shared understanding (Pasquire and Court 2013). Planning conversations in the 4-8 weeks before planned task delivery are particularly critical. Ramalingam and Mahalingam (2011) describe the role of boundary spanners who can facilitate conversations and the emergence of shared understanding.

\section{'Understanding' The Promise Cycle}

The simplified promise cycle shown in Figure 1 is critical to all forms of production (Flores 2013). It is at the heart of LPS. The structured LPS conversations are designed to make it easy for team leaders to make reliable promises about the work that they and their teams will do in the next period.

Customers make a request of one or more potential performers. Here's an example: 'Hey Mum, can we go for a bike ride today?' That's a request to one very special performer. If you are Mum, there may be other things you want to do today and that you expect your daughter to do, such as tidying her room. Thus begins a negotiation - what does she mean by bike ride (where, how long, when to leave, when due back) and what do you (Mum) understand by tidy room? Once you have agreed these things you can agree what will happen and when. In this case you will make promises to each other.

1. prepare

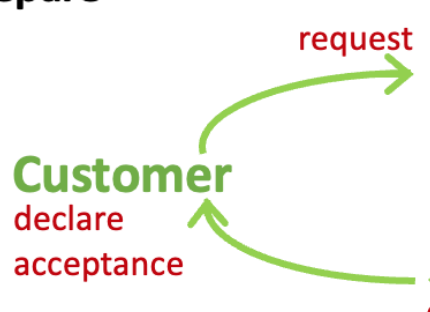

4. assess
2. negotiate conditions of satisfaction

Figure 1: The Promise Cycle (after Flores 2013)

In a work context, the complexity of the negotiation may be greater, yet the agreement of $\mathrm{CoS}$ and the delivery date are no less important. If this is not done, the assumptions made by the performer about the $\mathrm{CoS}$ may be wrong and the delivery may not satisfy the customer(s). CoS set out the customers' idea of quality work. If the next trade in line receives quality work, they are better placed to deliver quality work themselves.

\section{2 'UNDERSTANDING' THE CHALLENGES TO LEARNING: KNOWLEDGE TRANSFER ISSUES}

Construction projects bring together individuals and teams for a limited time to focus on creating a particular unique and complex outcome quickly. Construction work is embedded in institutionalized project settings where knowledge of regulations such as the operating laws, government rules, design and construction standards are explicit. Normative and cultural-cognitive knowledge such as work practices, local preferences and cultural beliefs tend to remain predominantly tacit (Javernick-Will and Levitt, 2010).

Drawn from different parts of an organisation and generally from a range of organisations, project participants, few of whom will have worked together before, must learn to share their diverse socio-technical expertise, skills and knowledge (Hayek 1945) 
so that they have a shared understanding of what is to be created. Most of the information and knowledge necessary to complete projects successfully is tacit (see fig. 2) and, according to Nonaka (1994), transfer of tacit knowledge can occur only through shared experiences such as socializing, mentoring or by providing on-the-job training.

On traditional projects, workers, or their trade supervisors, are instructed by site managers who tend to assume 1 . that the workers share their tacit understanding of what is required; 2. that they (the instructors) share the tacit knowledge of the requirements' authors and 3. understand the needs of later trades. Workers may also assume that they understand the instructions they receive.

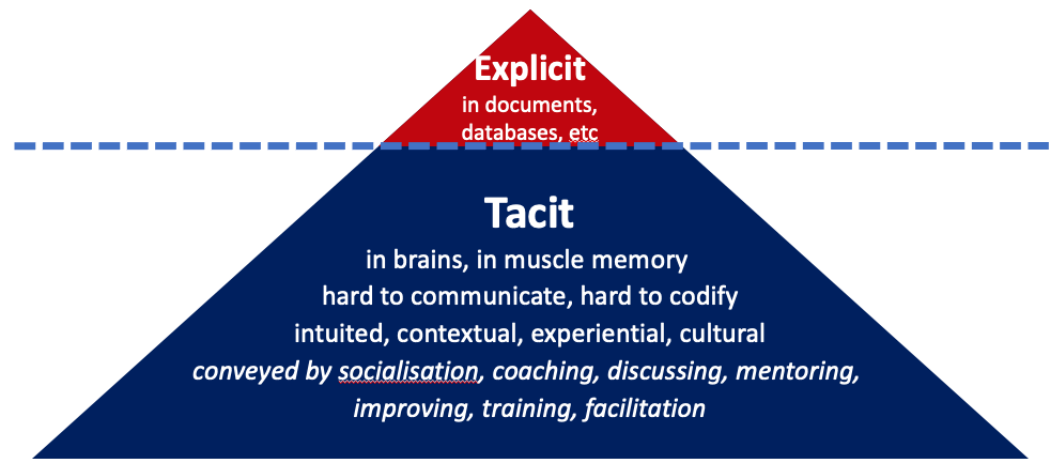

Figure 2: Tacit Vs Explicit knowledge in projects (after Nonaka 1994)

"Projects are embedded in multiple [systems] ... which jointly facilitate and constrain project organizing" (Manning 2008). The expectations of each individual's home team or organisation affects their willingness to trust others and share skills, information and knowledge, especially tacit knowledge. The structured conversations of LPS create shared experiences. The standardisation of the structured conversations between projects helps team members re-use their abilities to make their tacit understandings more explicit and to develop shared understandings as they move from project to project.

Leonardi and Bailey (2008) highlight the challenges to shared understanding for transnational teams due to differences in the interpretation of the implicit knowledge embedded in digital tools such as the meaning of the symbols or codes used in the tools.

\section{'Understanding' Psychological Safety Needs and Challenges}

Many workers feel that it is not safe say "no" to an instruction (Edmondson 1999 talks about psychological safety) or to say that they don't understand it, or the CoS. They feel they have to make-do, even when this results in sub-standard work. Edmondson (1999) says team 'psychological safety', a belief shared by team members that it is safe to take interpersonal risks, is a pre-requisite for learning. If nurtured carefully, psychological safety will result in a learning culture in which people feel free to speak up, ask for help, or offer an idea. In the face of uncertainty, the need to ask questions, tolerate mistakes and seek help become necessary competencies for learning, innovation and improvement.

\section{3 'UNDERSTANDING' REWORK, COST AND DELAY}

Rework becomes necessary when work done fails to match the expectations of a customer. Rework adds to project cost and duration. Tasks have to be completed or, more often, undone and redone using additional labour, materials, tools, equipment and time.

Rework disturbs production flow while the work is corrected. In manufacturing it is easy to insert buffers in the line so that briefly stopping the line in one section of the plant has no effect on other sections. In construction production that is much more problematic. 
If this happens too often, the authors' conversations in the field suggest subsequent crews add a time buffer between their start time and the previous crew's declared finishing time or they allow themselves more time to complete. In this way one small delay is magnified and completion is delayed.

Project leaders don't want production workfaces to be idle. Crew leaders don't want their workers waiting for work. The need for rework can result in either or both.

\section{SHARED UNDERSTANDING AND REWORK}

Figure 3 shows why shared understanding of the directives and CoS is important in a task production process if rework is to be avoided. The directives, including the CoS, are part of the request to the performer(s) of the task and are the basis for assessing the performer's output. Rework is likely to be required when the task output fails to meet the criteria.

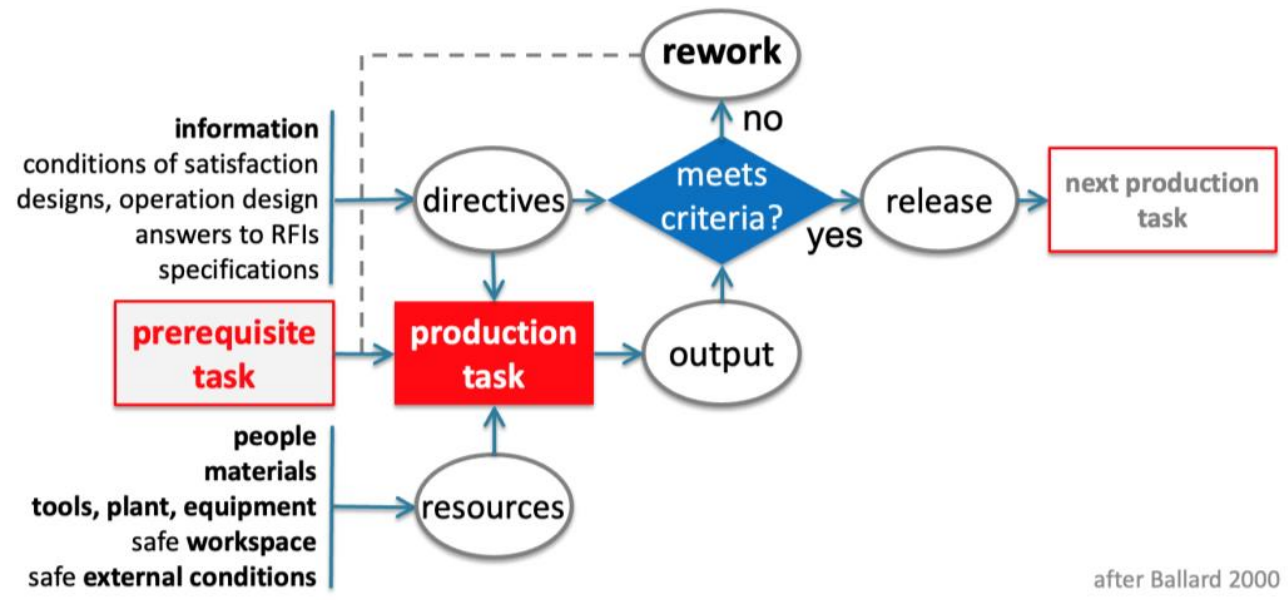

Figure 3: Activity Definition Model for task production (after Ballard 2000)

In order to do their work 'right first time', performers need to feel confident that they share their customers' understandings of the criteria. If performers' mis-understand the assessors' criteria, the assessors are likely to require at least additional work and possibly rework. Both result in additional cost and delay to the project overall as well as to the performer. Some performers understand that it is in their interest to ensure that they share the assessors' criteria so that they are better able to do tasks right-first-time.

Written documents and a number of people both within and outside the performers' immediate team hold the knowledge that performers need. Information about what their customers' value and the $C o S$ that are to be met will come, directly or indirectly, from those customers and via the directives for the task. Unambiguous and explicit directives and $\mathrm{CoS}$ are the ideal; in reality they will almost certainly refer to tacit knowledge, possibly assuming that it is explicit and shared (as in "everyone knows that!").

Directives and CoS may draw on normative and cognitive knowledge that could be tacit and open to interpretation. For instance, differences in institutionalized project settings and interpretations informed by tacitly held local norms and cultural beliefs can lead to differences in individual interpretations which create rework.

Information is not knowledge. Information may be shared. People can share experiences. A shared understanding of information requires dialogue between stakeholders to establish that it is shared. If you are told something (information) you need to experience it in some way so that it becomes your knowledge, and you have your understanding (Leonardi and Bailey, 2008). My understanding may not be the same as yours. That's why it's important to check that we have a sufficiently shared understanding. 


\section{DEVELOPING SHARED UNDERSTANDING}

Sharing information is a small but important part of building a shared understanding. Social processes enable performers to share their customers' understanding of what is required. Even if the task will be done by a robot, this social process is necessary to enable the person who programs the robot to understand how to set-up the robot.

The exchange and combination of information leads to the creation of intellectual capital and, as Nahapiet and Ghoshal (1998) suggest, can create organisational learning, a competitive advantage. In the context of projects there are two specific advantages: 1. the project specific advantage of reducing repetition of mistakes enabling the team to deliver the project for less - this aspect is limited to the project. 2. The meta-skill of learning to efficiently exchange and combine information producing a competitive advantage for those seeking to work together on future projects. Individuals can develop this skill and the consequent reputation as a good team player that goes with it - and so can companies, divisions, departments and crews that regularly work in projects.

Recent studies by Melissa Valentine and Michael Bernstein on "flash teams" temporary crowdsourced organisations fluidly convened through open call to solve complex problems quickly (See e.g. Hinds et al 2020) are, since the start of the COVID pandemic, relevant wherever teams have to learn effective online collaboration quickly.

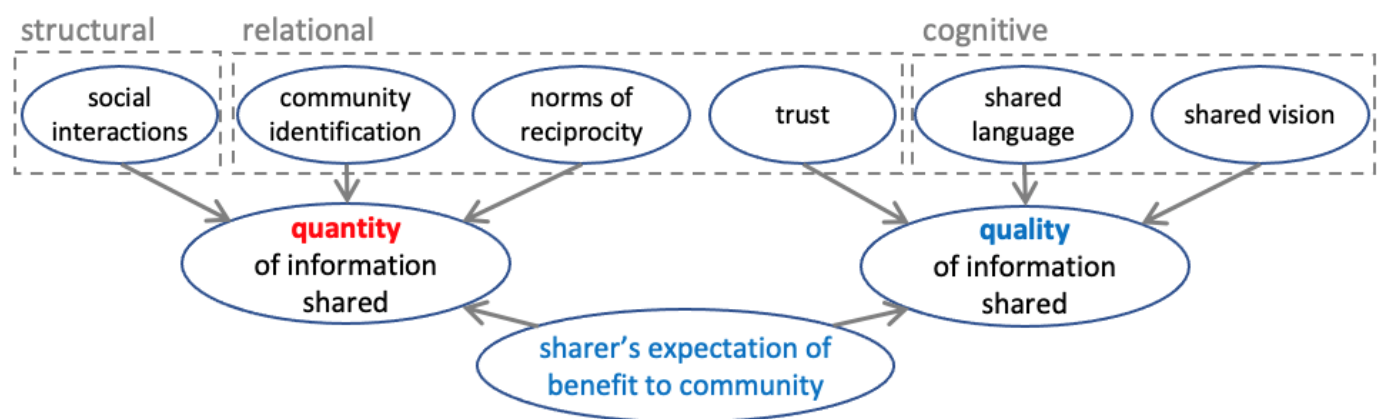

Figure 4: the significant drivers of information sharing. after Chiu et al (2006)

Figure 4 summarises the significant drivers of both the quantity and quality of information sharing. To show factors that affect the quantity and quality of information shared by individuals in virtual on-line communities, Chiu et al (2006) used selected drivers from Nahapiet \& Ghoshal's (1998) "dimensions of social capital": the quantity of knowledge shared is affected by Structural Social Interaction ties, the Relational norms around reciprocity and the degree to which the individual identifies with the community; the quality of the information shared is related to the degree the individual trusts the community, the Cognitive degree of shared language and shared vision. Project teams in the workplace, particularly with more people working from home post-COVID, have some similarities with virtual on-line communities.

How does a performer know what the customer wants? - and how does a performer know that they know what the customer wants? Production of understanding needs managing and because it involves both explicit and tacit knowledge, it is unlikely this understanding will simply exist. Pre-requisites for shared understanding include:

- parties understand that they need shared understanding.

- a psychologically safe way for each party to check that their understanding is sufficiently similar to each of the other parties such that they can be reasonably confident in the outcome. (This is necessarily a satisficing approach (Simon 1956) and presupposes that sometimes we will make mistakes.) 


\section{DISCUSSION}

Effective promising requires shared understanding of the customer requirements and CoS. Developing shared understanding is a critical step in making work ready in the Last Planner System. The initial conversations may happen during phase planning (or even earlier) as trade or design teams start to plan handovers from one to the next. On longlead items some discussion may be necessary prior to ordering to ensure that the supplies and sub-assemblies will meet the CoS. For all activities, $\mathrm{CoS}$ will be discussed once the activity is in the lookahead window. Absence of shared understanding of the CoS is a constraint on the successful delivery of a task or activity.

The most common metric used in LPS is PPC (Percentage of Promises Completed or Percent Plan Completed). The reason for publishing project PPC data is to help the team as a whole to learn. Everyday learning appears to offer teams a way to improve their LPS metrics such as PPC, Tasks Made Ready (TMR) and Commitment Level (CL) (Ballard \& Tommelein 2021). When PPC gets used as a stick to beat team members with, workers feel psychologically unsafe, learning stops and team member's attention shifts from advocacy for the project to protecting themselves from blame, claim or other sanctions.

For shared understanding performers need a way to check that they understand the intent of all the information they are given and the intent of their formal and informal customers. It is an example of reflective work that needs to precede execution.

When performers are clear about their customers' CoS, they are in a position to spot defects in their own work and correct it before passing it on to another trade. When actions are repeated (as in most projects) spotting defects early enables the responsible trade to do it right first time in future iterations - i.e. they don't repeat the mistake - as well as correcting the mistake(s) they made initially.

Even if they feel psychologically safe, it is not clear to us whether they will then be more likely to flag up defects - or things that don't look or feel right - in work being passed to them and get it put right before they do anything that would make corrections more difficult. In an ideal world, whether what they flag up is right or wrong, they will be thanked for asking the question. Then they will be more likely to do it again.

Shared understanding online: More and more construction work, particularly that involving designers, is now done online, a trend that COVID has accelerated. For some, this makes it easier to share ideas, information and knowledge. Sharing tacit knowledge as well as experiences (e.g. on local preferences, organizational norms, cultural beliefs) is easier when working face-to-face.

In short, based on all the above findings, 3 propositions are evident in this study which will have to be validated with future studies:

- Proposition 1: Less rework will be required when performers can develop a shared understanding of the Conditions of Satisfaction between negotiating parties

- Proposition 2: Shared understanding is most likely when the criteria are explicit

- Proposition 3: Everyday learning will help make tacit information more explicit.

\section{CONCLUSIONS}

In the preparation phase of the Promise Cycle, the customer develops $\mathrm{CoS}$ to sit alongside the request so that the potential performer knows what is expected. Negotiating the CoS involves making the knowledge explicit. The request + draft $\mathrm{CoS}$ is the signal for customer and performer to check that they have a shared understanding of the customer's 
$\mathrm{CoS}$ and, if necessary, to negotiate the $\mathrm{CoS}$ and/or the due date. That discussion will often require the sharing of tacit knowledge and implicit knowledge embedded in the tools in virtual contexts. Codification of the tacit knowledge and making explicit the imiplicit knowledge will help create shared understanding.

In LPS, the clarification and negotiation of the CoS happens at various stages, as the time for the work to be done approaches. Failure to (adequately) clarify the CoS with the performer increases the chances that the performer will get it wrong first time $\rightarrow$ leading to rework, delay and added cost.

Digitisation and online communication can facilitate collaborative transfer of knowledge but it does not guarantee shared understanding as it may erroneously assume shared implicit knowledge and tacit knowledge that is very difficult to share without dialogue, mentoring by knowledge workers or via hard negotiations.

Conditions that appear to facilitate shared understanding of $\mathrm{CoS}$ in any context include psychological safety, a project culture that makes time for it and an expectation that workers will not knowingly pass on defective work.

This suggests further propositions for future validation:

- Systematic root cause analysis of rework to establish if lack of shared understanding created the need for rework;

- What makes it easier/more difficult to share understanding of CoS in the context of a construction project - in design, in off-site fabrication, in assembly?

- How can we make it easier for project stakeholders to share tacit knowledge online and to recognise the importance of sharing implicit knowledge to mitigate risk?

- What makes it easier for workers to stop and correct defective work?

\section{REFERENCES}

Ballard, G. and Tommelein, I. D. (2021). Current Process Benchmark for the Last Planner® System of Project Planning and Control. Lean Construction Journal.

Ballard, H. G. (2000). The Last Planner System of Production Control. PhD Thesis. University of Birmingham.

Carrillo, P. (2005). Lessons learned practices in the engineering, procurement and construction sector. Eng, Construction \& Architectural Management,12, 236-50.

Chiu, Chao-Min, Meng-Hsiang Hsu, Eric TG Wang (2006). Understanding knowledge sharing in virtual communities: Decision Support Systems. 42, 1872-1888.

Edmondson, A. (1999). "Psychological Safety and Learning Behavior in Work Teams." Administrative Science Quarterly, 44 (2) 350-383.

Ferrada, X., Núñezb, D., Neyemb, A., Serpellc, A., Sepúlveda, M. (2016) A lessonslearned system for construction project management: a preliminary application, Procedia - Social and Behavioral Sciences 226, 302 - 309.

Flores, F. (2013) Conversations for Action and Collected Essays. Create Space.

Flores, G. (2016) Learning to Learn and the Navigation of Moods. Pluralistic Networks.

Gil, A. J. \& Mataveli, M. (2017). Learning opportunities for group learning: An empirical assessment from the learning organization perspective. J Workplace Learning, 29(1), $65-78$.

Green, Stuart D. (2011) Making Sense of Construction Improvement. Wiley Blackwell.

Hayek, F.A. (1945). The use of knowledge in society. Am. Econ Rev. 35(4) 519-30.

Hinds, R., Valentine, M., Berg, J., De Celles, K. (2020) Suddenly Seen: How Virtual Employees Experienced Newfound Equality and Visibility. Accessed February 26, 2021. https://mvalentine.github.io/pdfs/visibility.pdf. 
Javernick-Will, A and Levitt, R (2010) Mobilizing Institutional Knowledge for International Projects, ASCE J Construction, Engineering \& Management, 136(4).

Koskela, L., Pikas, E., Gomes, D., Biotto, C., Talebi, S., Rahim, N., \& Tzortzopoulos, P. (2016). "Towards shared understanding on common ground, boundary objects and other related concepts." In: Proc. 24th Ann. Conf. of the Int'l. Group for Lean Construction, Boston, MA, USA.

Leonardi PM and D.E. Bailey 2008 Transformational Technologies and the Creation of New Work Practices: Making Implicit Knowledge Explicit in Task-Based Offshoring MIS Quarterly 32(2):411-436.

Lincoln, F.H and Ahmed, S.M. (2020). Modern Construction: Lean Project Delivery and Integrated Practices, 2edn., Routledge.

Love, P. (2020). Creating a mindfulness to learn from errors: Enablers of rework containment and reduction in construction Development in the Built Env't 1.

Manning, S. (2008). Embedding Projects in Multiple Contexts: A Structuration Perspective Int'l J Project Management 26(1) 30-37.

Mossman, A. (2020). Last Planner: $5+1$ crucial \& collaborative conversations for predictable project production planning 40pp. Accessed March 8, 2021. http://bit.ly/LPS-am-2020.

Nahapiet, J, and Ghoshal, S. (1998) Social capital, intellectual capital, and the organizational advantage, Acad of Management Rev 23 (2) 242-266.

Nonaka, I. (1994) "A dynamic theory of organizational knowledge creation." Organisational. Science, 5(1) 14-37.

Pasquire, C. L. (2012) The $8^{\text {th }}$ Flow - Common Understanding. Proc 20th Annual Conference of the International Group for Lean Construction, San Diego, USA.

Pasquire C.L. \& Court, P.F (2013) An Exploration of Knowledge and Understanding the Eighth Flow. In Proc 21st Conf. of the Int'l Group for Lean Construction, Forteleza, Brazil.

Pasquire, C. \& Ebbs, P. 2017, 'Shared Understanding: The Machine Code of the Social in a Socio-Technical System' In: Proc. 25th Ann Conf of the Int'l Group for Lean Construction. Heraklion, Greece, 9-12 Jul 2017. pp 365-372.

Ramalingam, S and Mahalingam, A. (2011). Enabling conditions for the emergence and effective performance of technical and cultural boundary spanners in global virtual teams. Engineering Project Org. J. 1(2).

Simon, H. A 1956 "Rational Choice and the Structure of the Environment" Psychological Rev. 63(2) 129-138.

Sutton, R. I and Staw, B.M. (1995) What Theory is Not. Admin Sci Q, 40(3) 371-84.

Torraco, R. J. (1997). "Theory-Building Research Methods." In Swanson R.A. \& E.F. Holton, eds. Human Resource Development Research Handbook. Berrett-Koehler. 